\title{
O FEEDBACK COMO FERRAMENTA AVALIATIVA E MOTIVADORA NO PROCESSO DE AQUISIÇÃO DE LÍNGUA ESTRANGEIRA
}

\author{
(Feedback as an evaluative and motivational tool in the process of acquisition of a foreign \\ language)
}

\author{
Carmem Silvia Lima Fluminhan ${ }^{1}$ \\ UNOESTE \\ Camélia Santina Murgo ${ }^{2}$ \\ UNOESTE \\ Antonio Fluminhan ${ }^{3}$ \\ UNOESTE
}

\begin{abstract}
RESUMO
O objetivo geral desta pesquisa bibliográfica é de apresentar e discutir estudos que investigam a relevância e o uso do feedback pelo professor como ferramenta avaliativa e motivadora no processo de aquisição de língua estrangeira. Inicialmente, discute-se a origem do termo feedback e são apresentados os diferentes tipos de feedback, bem como a sua importância para o processo de ensino $e$ aprendizagem. Essa pesquisa discute como o feedback acontece nos trabalhos escritos e no desempenho oral do aprendiz e qual deve ser a postura do professor como principal mediador do processo de aprendizagem. Por tratar-se de um momento comum durante a aquisição de uma língua estrangeira, é dado um enfoque especial ao tratamento do feedback na escrita e em atividades orais, tanto em contexto de sala de aula quanto em atividades desenvolvidas em ambientes externos à escola. Finalmente, o feedback como ato de comunicação e a função do feedback entre os pares são discutidos com base em relatos na literatura nacional e internacional. Os dados indicam que um feedback abrangente e completo promovido pelo professor é significativo para as atividades de avaliação, dentro de uma prática pedagógica, com vistas a conduzir o aluno à efetiva aprendizagem do idioma inglês como língua estrangeira.
\end{abstract}

Palavras-chave: Feedback. Ensino e aprendizagem. Avaliação. Língua estrangeira. Motivação.

\section{ABSTRACT}

\footnotetext{
${ }^{1}$ Possui graduação em Letras - Licenciatura Inglês/Português e em Tradução e Interpretação pela Faculdade Ibero-Americana de Letras e Ciências Humanas, Aperfeiçoamento em Desenvolvimento de Docentes Proficiency pelo SENAC - SP. Obteve o Certificate of Proficiency in English pela University of Cambridge (Reino Unido). Realizou curso de Especialização em Avaliação do Ensino e da Aprendizagem e curso de Mestrado em Educação pela Universidade do Oeste Paulista (UNOESTE). E-mail: fluminhan@unoeste.br

2 Possui graduação e licenciatura em Psicologia pela Universidade do Sagrado Coração, Mestrado em Psicologia Escolar e Doutorado em Psicologia Ciência e Profissão pela Pontifícia Universidade Católica de Campinas. Pósdoutorado em Avaliação Psicológica pela Universidade São Francisco. É docente e Coordenadora do Programa de Pesquisa e Iniciação Cientifica do Curso de Psicologia da Universidade do Oeste Paulista. Foi coordenadora do Programa de Pós-Graduação em Educação da Universidade do Oeste Paulista (UNOESTE). E-mail: camelia@unoeste.br

${ }^{3}$ Possui graduação em Engenharia Agronômica pela ESALQ / USP, Especialização em Biotecnologia pelo Instituto RIKEN, Japão, Mestrado em Genética e Melhoramento pela ESALQ/USP, Doutorado em Genética e Fisiologia Celular pela Tohoku University, Japão e pós-doutorado no Departamento de Biociências do Instituto RIKEN, Japão. Desde abril de 1999 é professor e pesquisador na Universidade do Oeste Paulista (UNOESTE), onde ocupa também o cargo de Assessor de Relações Interinstitucionais e Editor da revista científica Colloquium Vitae. E-mail: fluminhan@unoeste.br
} 
The main objective of this bibliographic research is to present and discuss studies that investigate the relevance and the use of feedback offered by the teacher as an evaluative and motivational tool in the process of acquisition of a foreign language. Firstly, the definition and the origin of the term feedback are discussed, and the different types of feedback are presented, as well as their concepts and the detailed descriptions of their importance in the process of teaching and learning. This research presents how feedback is provided in the student's written work and oral performance and what the teacher's attitude is supposed to be as the main mediator in the learning process. As feedback consists of an extremely common tool during the acquisition of a foreign language, this study focus specially on the treatment of feedback in written and oral activities, both for assignments developed in classroom and out of school contexts. Additionally, the present research brings feedback as an act of communication and its effectiveness in peer feedback based on national and international studies. The data indicates that a comprehensive and coomplete feedback offered by teachers is significative in evaluation activities, inserted into a pedagogical practice, favouring students to learn English as a foreign language.

Keywords: Feedback. Teaching and learning. Evaluation. Foreign language. Motivation.

Recebido em: maio 2017

Aceito em: julho 2018

DOI: $10.26512 /$ les.v19i2.16810

\section{INTRODUÇÃO}

Em diversos aspectos da atividade humana, em diferentes momentos em que há comunicação, é necessário que haja um feedback entre o emissor e o receptor da informação (ou retroalimentação, na tradução livre para o idioma português), seja para confirmar o que foi emitido, seja para orientar novas práticas ou para corrigir o que já foi executado. $\mathrm{O}$ feedback tem-se revelado como um importante mecanismo para a certificação de que tanto o emissor quanto o receptor da mensagem estão "em sintonia" ou, na expressão mais moderna, estão "conectados" entre si. Desta forma, a presente pesquisa bibliográfica tem como objetivo geral apresentar e discutir estudos que investigam a relevância e o uso do feedback como ferramenta avaliativa e motivadora no processo de aquisição de língua estrangeira. Para tanto, serão apontados os diferentes tipos de feedback, os seus conceitos e as descrições detalhadas de sua importância para o processo educacional. Em especial, será dada ênfase ao processo de ensino e de aprendizagem de um idioma estrangeiro.

No modelo de ensino de idioma presencial em que o professor está em contato direto com os alunos, a utilização do feedback é de suma importância para inúmeras situações, tais como: responder dúvidas, avaliar e acompanhar o aprendiz no desenvolvimento das quatro habilidades do idioma (ouvir, falar, ler e escrever) de forma motivadora, que impulsione o aluno a alcançar os seus objetivos. Sendo a escrita uma habilidade indispensável para a aquisição de um idioma estrangeiro, será dado um enfoque especial ao feedback na escrita, ou 
seja, ao modo como o professor fornece retorno ao aprendiz em relação a uma atividade escrita. Ao final, com base nos resultados obtidos nesta pesquisa, e na extensa discussão da literatura especializada, serão propostas sugestões práticas de feedback com a finalidade de auxiliar docentes de língua estrangeira na execução desta importante ferramenta de comunicação, correção e motivação.

Para a realização da presente pesquisa foram consultadas publicações na literatura especializada e que estão disponíveis em bases de dados indexadas internacionalmente. As pesquisas bibliográficas permitiram reunir um significativo número de publicações que envolveram: livros, dissertações e teses de cursos de pós-graduação stricto-sensu, artigos completos publicados em periódicos nacionais e internacionais, monografias de especialização e apresentações de palestras com acesso livre através da internet.

Constatou-se que há um reduzido número de publicações realizadas no Brasil e, deste modo, procurou-se dar um enfoque analítico à pesquisa, respeitando-se as diferenças existentes em cada um dos estudos publicados, em relação ao grau de conhecimento dos docentes e coordenações de cursos, níveis de escolaridade dos discentes, utilização de recursos de tecnologia de informação, entre outros.

\section{A FERRAMENTA FEEDBACK}

Feedback é comumente descrito como a resposta ou a atitude de uma pessoa em relação a uma ação emitida pelo aprendiz e que pode auxiliá-lo a avaliar e/ou melhorar seu desempenho no futuro (KEH, 1990; COHEN; CAVALCANTI, 1990; SCHERMAN, 1994; DHERAM, 1995; UR, 1996; JAMES, 1998).

O termo feedback foi originalmente cunhado na área de biologia para referir-se ao processo de resposta que o organismo realiza após interagir em seu ambiente (RINVOLUCRI, 1994). Segundo o autor, trata-se de um processo neutro, uma resposta na cadeia de ação e reação. Denomina-se feedback o mecanismo de homeostase, termo criado em 1926 pelo fisiologista norte-americano Walter Bradford Cannon (para uma revisão sobre o tema, veja SOUSA; SILVA; GALVÃO-COELHO, 2015). Em sua descrição original, o termo homeostase ou homeostasia descreve o mecanismo de um sistema aberto, que ocorre predominantemente nos seres vivos, com o objetivo de regular o seu ambiente interno para manter uma condição estável, através de múltiplos ajustes de equilíbrio dinâmico, controlados por mecanismos de regulação inter-relacionados (SOUSA; SILVA; GALVÃO-COELHO, 2015; BRITO, HADDAD, 2017). A homeostase é uma das características fundamentais dos seres vivos, pois depende dela para realizar a manutenção do equilíbrio interno dentro de 
limites toleráveis Entretanto, atualmente esse termo é amplamente utilizado em áreas distintas, tais como informática, propaganda e marketing e educação, porém seu sentido inicial não foi perdido.

Diversos pesquisadores da área de educação propuseram diferentes definições para o termo feedback no contexto de ensino e de aprendizagem. Para Vrasidas e McIsaac (1999), feedback é o conjunto de respostas que o professor fornece ao aluno sobre a correção das diferentes atividades solicitadas, como, por exemplo, deveres de casa, trabalhos extra classe e contribuições em sala de aula. Esta definição de feedback pode ser tanto utilizada em contextos presenciais como em ambientes on-line. Entretanto, segundo os autores, o feedback ainda encontra-se restrito à correção de tarefas e às contribuições dos alunos.

O termo feedback foi definido por Hattie (1993) como sendo uma ferramenta para orientar o aluno em relação ao seu desenvolvimento acadêmico, através de informações acerca de sua habilidade ou inabilidade em compreender o que está sendo estudado. Mason e Bruning (2003) definem feedback como qualquer ato emitido em resposta a ação do aluno. Os autores, assim como Vrasidas e McIsaac (1999), também tratam o feedback em contextos presenciais e on-line. Entretanto, esta definição é mais abrangente, pois não se limita às tarefas e contribuições dos alunos, e, sim, mensagens em resposta a qualquer ato do aprendiz.

Para Shute (2007), o feedback deve assumir um papel formativo no contexto educacional. A autora define o termo feedback como sendo toda informação comunicada ao aluno com o intuito de modificar seu pensamento ou comportamento a fim de promover aprendizagem. Ainda, segundo esta autora, o feedback formativo tem como objetivo aumentar o conhecimento, as habilidades e a compreensão do aprendiz em relação ao conteúdo trabalhado. No contexto on-line, a mesma autora considera que o feedback formativo é toda informação oferecida ao aluno, por meio de uma mensagem, display, vídeo, áudio, entre outros meios, em resposta a uma ação do aluno (contribuições, tarefas dirigidas, questionamentos etc.) que tenha como alvo moldar sua percepção, ação e cognição, para facilitar sua aprendizagem e favorecer seu desenvolvimento. Entretanto, ao tratar o feedback como uma ferramenta que busca modificar o pensamento ou o comportamento do aprendiz, ocorre um retrocesso do feedback a uma visão behaviorista de ensino e aprendizagem.

Paiva (2003) apresenta uma investigação específica para feedback em ambiente de ensino e aprendizagem on-line. De acordo com a autora, feedback é a resposta à presença ou ausência de alguma ação com o objetivo de avaliar ou pedir avaliação sobre a performance no processo de ensino e de aprendizagem e de refletir sobre a interação de forma a motivá-la, controlá-la ou avaliá-la. A definição da autora é bem mais abrangente do que as anteriores, 
pois considera que o feedback pode ser fornecido não apenas pelo professor, mas também por um colega ou até por outro agente alheio ao processo de aprendizagem, e, por esta razão, a autora dispensa o uso de expressões como professor, aprendiz, aluno e computador.

A partir desta discussão inicial, pode-se afirmar que o feedback é um importante recurso no processo de ensino e de aprendizagem, tanto em ambientes presenciais quanto em contextos educacionais on-line. Entretanto, aliado aos problemas decorrentes do fato de o professor não estar completamente engajado em usar o feedback em suas práticas avaliativas por desconhecer sua importância e eficácia, Flores (2009) e Cardoso (2011), ressaltam ainda a inexistência, na atualidade, de um mecanismo por parte das direções das instituições de ensino e das coordenações pedagógicas que incentive e até mesmo que adote o feedback como instrumento pedagógico compulsório em seus planos de ensino.

\section{O FEEDBACK COMO ATO DE COMUNICAÇÃO}

Segundo Gus (2001), o feedback é caracterizado por dois componentes distintos: a avaliação e a correção. De acordo com a autora, o feedback avaliativo é aquele no qual o professor fornece uma nota, conceito ou algum comentário a respeito da atividade realizada pelo aprendiz. Por sua vez, o feedback corretivo é o retorno fornecido pelo professor em que são enfocados aspectos informativos sobre o desempenho do aprendiz, ou seja, o professor apresenta correções, comentários e aponta a natureza do erro, permitindo ao aluno que revise seu trabalho, reformule-o e corrija-o de forma eficaz e consciente.

Tendo em vista que a comunicação vai além da função de traduzir e exteriorizar um pensamento ou transmitir informações, Gus (2001) recorda que o ato de comunicação está intrinsecamente ligado a realizações de tarefas, ação e atuação sobre o interlocutor. Desta forma, entende-se que o feedback é uma forma ou processo de interação.

Ao compreender feedback como um ato de comunicação, Bordenave (1982) constata que aquele traz consigo a inerente característica de atuar sobre a realidade ou situação onde é empregado, produzindo um efeito transformador sobre os interlocutores. Segundo o autor, no caso de ensino de língua estrangeira, especificamente, o professor deve utilizar todos os recursos da linguagem para compreender as expectativas e necessidades de seu público alvo, acompanhar e orientar seu aprendiz e motivá-lo a conquistar seus objetivos.

Considera-se ainda que o tempo de retorno, o tipo e a qualidade do feedback ofertado pelo professor são outros aspectos que estão diretamente relacionados ao bom uso deste recurso avaliativo e corretivo, cooperando para o sucesso do ensino e da aprendizagem (CARDOSO, 2011). O professor deve usar o feedback para demonstrar ao aluno que este não está sozinho ou 
desamparado durante sua caminhada na aquisição da língua estrangeira. A omissão do professor em promover constante feedback poderá ser interpretada pelo aluno como abandono e ausência de orientação, gerando desânimo e insegurança por parte do aprendiz (FLORES, 2009).

O feedback como ato de comunicação torna o professor sempre "presente", conferindo não somente intencionalidade pedagógica à atividade em questão, mas também, e principalmente, garantindo ao aluno o acompanhamento assistido, fundamental para que este possa atingir todo o seu potencial de desempenho (CARDOSO, 2011).

Observa-se ainda que há uma forte relação entre o recebimento de feedback, sua motivação e qualidade. Segundo o relato de Williams (2005), o feedback é fundamental para todas as relações interpessoais. É através desta ferramenta que podemos perceber como as pessoas pensam, o que sentem, de que forma reagem aos outros e, em grande parte, é o que determina como as pessoas encaram suas responsabilidades do cotidiano.

Quando o professor se omite em apresentar retorno ao aluno, ocorre um sentimento de desamparo, de vazio. No caso da aquisição de uma língua estrangeira, o resultado que se observa é o enfraquecimento e até mesmo a quebra dos laços de confiança entre o professor e o aprendiz (FLORES, 2009). Vale também considerar que o professor não pode estar sozinho na missão de utilizar o feedback com eficiência e consistência durante o processo de ensino e de aprendizagem. Também é função das direções de ensino das instituições, bem como de suas respectivas coordenações pedagógicas acompanhar, orientar, treinar e reciclar os professores, capacitando-os na utilização do feedback como recurso avaliativo, corretivo e motivacional durante o processo educacional e, desta forma, garantir a utilização adequada desta importante ferramenta pedagógica. Caso contrário, corre-se o risco de os professores minimizarem a importância do feedback por falta de conhecimento sobre o assunto, por excesso de trabalho, por falta de tempo em sala de aula ou até mesmo por sentirem-se desmotivados.

\section{FORMAS DE FEEDBACK}

Existem muitas teorias sobre os tipos ou formas "ideais" de feedback amplamente reconhecidas em literatura especializada, assim como suas classificações variam de acordo com o autor ou pesquisador em questão. O importante é que o feedback emitido seja realmente claro, que comunique com eficácia o que se deseja e que seja útil para o aprendiz (GUS, 2001). Assim sendo, ainda segundo a autora, o professor estará usando de suas atribuições para acompanhar e direcionar seu aluno, estará alimentando, isto é, feeding o aprendiz com comentários, instruções, correções e questionamentos que objetivam fazê-lo refletir sobre suas produções linguísticas, seu 
comportamento frente aos estudos e suas reais metas na aprendizagem da língua estrangeira. Para que isto aconteça, é primordial que exista um constante diálogo entre o professor e o aprendiz.

Scherman (1994) apresenta três classificações de feedback: correções feitas pelo professor, comentários fornecidos pelo mesmo e uma nota ou conceito apresentados. Para o autor, o feedback ideal é aquele em que o professor tem a oportunidade de reunir-se individualmente com cada aprendiz, dispõe de um ambiente favorável para dialogar, fazer sugestões e ouvir possíveis questionamentos por parte do aprendiz. É um momento propício para que haja o estreitamento da relação de confiança e de comprometimento entre o professor e o aprendiz. A esta forma de feedback é dado o nome de "conferência".

A conferência permite uma personalização do feedback e torna cada aprendiz único naquele momento. Implica em uma maneira simples, esclarecedora e extremamente eficaz de se resolver e até mesmo de se antever problemas. Talvez seja este o melhor momento para que o professor motive seu aprendiz, exalte as qualidades e os esforços dos que já estão trilhando o caminho certo, que faça nítidos cumprimentos aos que se destacam, sem temer que haja comparações e, consequentemente, sem que se provoque constrangimento entre os pares (JAMES, 1998). No entanto, as evidências apontam para o fato de que este tipo de feedback não é facilmente adotado devido à escassez de tempo em sala de aula, ao desconhecimento de sua eficácia e à falta de apoio por parte das instituições de ensino (GUS, 2001).

Hadley (2001) afirma que, seja qual for o contexto educacional em questão, é muito difícil determinar qual o melhor feedback a ser utilizado. O tipo de feedback deve levar em consideração a forma como cada aprendiz reage, pois sabe-se que cada um apresenta um estilo diferente de aprendizagem, e consequentemente reage de formas distintas ao feedback, assim como cada professor é único em sua maneira de ensinar e demonstra ter mais afinidade por um ou outro tipo de feedback.

\section{O FEEDBACK NA ESCRITA}

Dvorak (1986) e Hadley (2001) definem a escrita como sendo todas as ações em que ocorre a transferência do pensamento para o papel. O processo da escrita envolve várias etapas diferentes, desde a busca inicial das informações, as idéias a serem desenvolvidas, a produção, a revisão até a finalização ou mesmo a sua publicação. Segundo Hedge (2001), mesmo adultos falantes nativos da língua consideram escrever uma habilidade complexa.

O uso crescente da internet como meio de comunicação tem provocado mudança de atitude por parte de aprendizes e professores em relação à escrita. Em decorrência do avanço tecnológico, a 
escrita está ocupando um espaço cada vez mais relevante em cursos de idiomas e, portanto, não podemos negligenciá-la, como ocorreu quando houve a supervalorização das metodologias comunicativas. (GUS, 2001).

o entanto, para melhorar a escrita, é fundamental praticá-la insistentemente. Quanto mais esta habilidade é exercitada, mais fácil e eficaz será sua plena aquisição (GUS, 2001). O desenvolvimento da escrita faz-se através da experiência em escrever, rascunhar, revisar e reformulá-lo novamente. Pan (1980) afirma que para escrever bem é preciso escrever e ler assiduamente. Antes de exigir que os alunos escrevam bem, devemos motivá-los a escrever, pois é somente através da prática que atingimos o objetivo desejado.

Hyland (1990) recomenda que o professor restrinja seus comentários àquilo que julgar prioritário em cada etapa do processo de aprendizagem, pois o aluno não terá maturidade e conhecimento prévio consistente para entender todos os problemas existentes de uma só vez. Autores como Hendrickson (1978), Byrne (1988), Edge (1989) e Ur (1996) concordam que não é importante corrigir cada erro do aprendiz e que a correção em excesso pode ser desmotivadora.

Ressalta-se, ainda, o fato de que muitas vezes o aluno se comporta de forma descompromissada em relação a sua própria aprendizagem e que o retorno dos trabalhos escritos é com muita frequência desmotivadora também para o professor. Muitos docentes, segundo Hyland (1990), relatam que corrigir, comentar e fazer sugestões e anotações nas redações de seus alunos é um trabalho não apenas cansativo, mas também desestimulante. Por outro lado, o autor afirma que se o aprendiz compreender como receber e, consequentemente, como trabalhar mais eficazmente com o feedback, este pode vir a ser uma ferramenta aliada para a aquisição do conhecimento.

Sendo assim, os critérios devem ser consistentes, abrangentes e claros e os aprendizes devem ser esclarecidos sobre o porquê de estarem sendo avaliados desta forma (ABAURRE; ABAURRE, 1999) e qual é a atitude esperada por parte do aluno frente à correção e ao feedback ofertados pelo professor (HYLAND, 1990).

\section{O FEEDBACK E A ATITUDE DO PROFESSOR}

Kielty (2004) afirma que há uma clara relação entre a percepção do feedback por parte dos alunos e a retenção dos mesmos. A autora conclui que simplesmente receber um feedback por parte do professor é considerado tão importante quanto a qualidade do feedback.

Relatos na literatura especializada têm enfatizado a grande influência que adultos, principalmente professores e pais, exercem no desenvolvimento pessoal dos alunos (PORLIER; SAINT-LAURENT; PAGE, 1999). O autor investigou a relação da atitude de professores, assim 
como de outras pessoas que convivem com as crianças como pais, irmãos, e colegas, e a autoestima da criança. A qualidade de vida em sala de aula tem sido considerada de fundamental importância para os alunos (THORP; BURDEN; FRASER, 1994). Os autores estabeleceram que há relação entre a satisfação que os alunos revelam ter no ambiente de sala de aula e o feedback e elogios oferecidos pelo professor.

O termo 'elogio' é derivado do verbo do latim pretiare, e significa considerar de alto valor, valorizar (SHERPELL, 2000), e envolve o ato de atribuir valor a um indivíduo ou expressar admiração ou aprovação (BLOTE, 1995). Segundo o autor, o elogio do professor contém afeto positivo, e é uma resposta mais intensa e detalhada ao comportamento do aluno quando comparado ao feedback. Pesquisas realizadas por Hitz e Driscoll (1988) a respeito da atitude do professor em um contexto educacional consideram que o elogio em sala de aula ocorre quando o professor se refere de forma positiva ao trabalho desenvolvido pelo aluno. Os autores apontam que esta atitude exige que os professores sejam não-julgamentais em seus comentários para que os próprios alunos não atribuam conceitos entre si ou a si mesmos.

Em estudos acerca do assunto, Hitz e Driscoll (1994) sugerem que os professores promovam elogios construtivos para favorecer o desenvolvimento da autoestima nos alunos. E para que isto ocorra, segundo os autores, é necessário reconhecer os avanços e esforços dos alunos, promovendo comentários sinceros e levando em consideração seus sentimentos. Nessa mesma concepção, Thomas (1991) refere-se ao elogio como sendo um reforço positivo e consistente com o objetivo de incentivar comportamentos positivos e eliminar atitudes indesejáveis. O autor sugere que o elogio seja utilizado como um instrumento motivacional em sala de aula e que seja descritivo, além de incluir o nome do aluno. Para tal, ainda segundo o autor, o professor deve selecionar as palavras cuidadosamente e descrever com acuidade o comportamento merecedor do elogio.

Brophy (1981) aponta que o elogio tem sido amplamente recomendado como um importante método de reforço utilizado pelos professores em ambiente de imersão de língua estrangeira, pois ele constrói a autoestima, promove a motivação e facilita a aproximação entre o professor e o aluno. Entretanto, em oposição ao que a literatura especializada recomenda, o elogio no contexto pedagógico ocorre com baixa frequência (THOMAS et al., 1978; LUCE; HOGE, 1978). Estudos realizados por Dunkin e Biddle (1974) revelam que o elogio acontece, em média, em apenas 6\% do tempo de sala de aula. Brophy (1981) argumenta que a prática do elogio em sala de aula como ferramenta motivadora está diretamente relacionada ao perfil e à personalidade do professor, além da percepção que o docente tem da necessidade que os alunos demonstram em receber elogios. Em contraste aos estudos realizados por Brophy (1981) que apontam a baixa 
freqüência de elogios por parte dos professores, pesquisas conduzidas por Lyster e Ranta (1997) sugerem que os professores oferecem elogios frequentes e consistentes aos seus alunos.

Strain et al. (1983) afirma que apesar da oferta de feeback promovida pelo professor ser, em geral, baixa, os professores tendem a ofertar mais feedback negativo do que positivo aos seus alunos. Ao contrário dos resultados apurados pelo último autor, Merrett e Wheldall (1987) observaram 128 professores na Inglaterra e verificaram que 56\% do feedback oferecido pelos professores era positivo, enquanto $44 \%$ era negativo. Ainda segundo os autores, em relação aos comportamentos acadêmicos, os professores fizeram três vezes mais comentários positivos do que negativos e em relação a comportamentos sociais, os comentários negativos foram cinco vezes mais frequentes do que os positivos. Merrett e Wheldall (2006) revelam que as professoras tendem a ofertar mais comentários negativos aos alunos do sexo masculino acerca de comportamentos sociais, enquanto os professores do sexo masculino tendem a oferecer mais comentários positivos aos alunos do sexo masculino em relação ao comportamento acadêmico.

Thorp, Burden e Fraser (1994) afirmam que os alunos passam aproximadamente 15.000 horas em sala de aula durante os ensinos fundamental e médio. Desta forma, segundo os autores, é importante que os alunos tenham boas experiências e sintam-se bem no contexto escolar. Um ambiente educacional positivo, agradável e acolhedor tem sido diretamente relacionado ao sucesso acadêmico alcançado pelos alunos (FRASER, 1991); à melhora do rendimento escolar de crianças que vivem em condições de risco (WENTZEL, 1994); ao perfil e à personalidade do professor e aos efeitos positivos na motivação, nas atitudes e no comportamento interpessoal dos alunos (BATTISTICH et al., 1996).

Enfim, pesquisas revelam que um relacionamento positivo entre professor e aluno é um importante aspecto que gera um ambiente de sala de aula positivo (WUBBELS; LEVY, 1993; BIRCH; LADD, 1997). Pianta e Walsh (1996) e Wang, Haertel e Walberg (1994) enfatizam a importância de se cultivar um bom relacionamento entre o professor e o aluno, e que este relacionamento deve ser encorajador, motivacional e, ainda, que o professor deve demonstrar real interesse pelo sucesso do aluno.

\section{O FEEDBACK ENTRE OS PARES}

A literatura especializada tem amplamente revelado que aprendizes de idioma estrangeiro enfrentam dificuldades ao se expressarem de forma oral e escrita no idioma que estão estudando (GUS, 2001; THAC Sĩ, 2008;). Como resultado, a qualidade, a precisão e a fluência dos textos escritos por alunos de idioma estrangeiro é, em sua maioria, muito baixa. 
Thac Sĩ (2008) afirma que a quantidade de redações exigidas pelos professores é insuficiente para que os alunos desenvolvam a habilidade de escrever com sucesso. $\mathrm{O}$ autor aponta que uma outra razão pela qual os alunos demonstram ter pouco interesse em escrever pode estar relacionado a pouca, e, em certos casos, a nenhuma oportunidade oferecida aos aprendizes para a aprendizagem em cooperação entre os pares. Na realidade, segundo o autor, os alunos recebem feedback majoritariamente de seus professores e raramente de seus colegas.

Até mesmo quando o feedback é ofertado pelo professor, eles tendem a gerar ambiguidade ou a serem muito vagos em seus comentários, como Coupe (1986) exemplifica: “Good Job” (Bom trabalho), ou "You should try more" (Você deve se esforçar mais). Segundo Thac Sĩ (2008), isto se deve ao fato de que os professores geralmente tem pouco tempo para promoverem um feedback específico. Além disso, normalmente os alunos não compartilham suas redações com seus pares, nem tampouco, se dedicam em revisá-las. $\mathrm{O}$ autor argumenta ainda que, por este motivo, os alunos continuam cometendo os mesmos erros várias vezes e desperdiçam a oportunidade de aprenderem através dos erros ou dos comentários de seus pares.

Schriver (1989) afirma que para que os alunos progridam em sua habilidade escrita, é fundamental que estes incorporem em seus hábitos de estudo a prática da revisão das redações após a correção. Além disso, segundo o autor, é necessário que os alunos reescrevam seus textos já corrigidos e revisados utilizando o feedback ofertado pelo professor. No entanto, segundo Thac Sĩ (2008), os alunos são raramente solicitados a revisarem e reescreverem suas redações baseados no feedback promovido pelo professor. Geralmente a primeira redação torna-se também a última. $\mathrm{O}$ autor reconhece que corrigir novamente a mesma redação do aluno significa, para o professor, duplicar sua carga de trabalho. Por esta razão, o autor argumenta que os alunos estão perdendo uma chance ímpar de desenvolverem esta habilidade de forma crítica e eficaz.

Estudos realizados por Thac Sĩ (2008) apontam que os alunos de língua estrangeira também sentem-se desmotivados para praticarem atividades escritas por perceberem que seus textos não serão lidos por um “público real”. Sendo assim, eles escrevem apenas para seus professores, e isto acontece somente quando são solicitados a realizarem uma atividade avaliativa, ou seja, para obterem nota ou conceito na disciplina. Neste caso, segundo o autor, as redações costumam ter temas direcionados pelo professor, geralmente referindo-se ao assunto abordado pela unidade que está sendo estudada em sala de aula. O autor, então, defende que o professor de língua estrangeira deve ser menos "controlador" ao sugerir os temas das redações e permitir que a criatividade dos alunos seja efetivamente explorada, gerando maior motivação e envolvimento dos alunos.

Estudos acerca do papel do feedback entre os pares em atividades escritas têm demonstrado que este recurso é bastante eficiente quando aplicado no ensino de inglês como língua 
estrangeira (LANGAN; WHEATER, 2003; TRAHASCH, 2004; CHO; SCHUNN, 2005; ERTMER et al., 2007).

Thac Sĩ (2008) afirma que graças ao desenvolvimento tecnológico, várias universidades e instituições de ensino têm adotado esta ferramenta pedagógica on-line. Teoricamente, o feedback entre os pares é um tipo de aprendizagem colaborativa em que os alunos aprendem a analisar e, em seguida, oferecem um feedback construtivo aos seus pares em atividades escritas (TRAHASCH, 2004). Thac Sĩ (2008) afirma que, a fim de economizar tempo em sala de aula e de promover um ambiente menos estressante, muitos professores de inglês como língua estrangeira têm usado o "Sistema On-line de Correção Entre os Pares" (OPAS, sigla do inglês para 'Online Peer Assesment System'). Ainda, segundo o autor, este sistema é o mais apropriado para cursos de idioma inglês como língua estrangeira, pois objetiva enfatizar a aprendizagem tanto individual como coletiva do grupo. Isto acontece por que os alunos precisam oferecer feedback aos seus pares de forma escrita, e, desta forma, estarão praticando mais uma vez sua habilidade de escrever de maneira clara e eficiente.

Enfim, para que o aluno seja mais estimulado a escrever e melhore sua capacidade de se expressar de forma escrita, é recomendado que o professor institua em sua prática pedagógica a oferta de feedbacks claros, objetivos, motivadores e corretivos, que incentive seus alunos a realizar a revisão de suas redações, reescrevendo seus textos utilizando-se do feedback promovido pelo professor e que os alunos tenham a oportunidade de realizar o feedback entre os pares (THAC SĨ, 2008).

\section{OS FEEDBACKS AVALIATIVO, CORRETIVO E MOTIVADOR}

Ao expor-se a um idioma desconhecido, ou pelo menos ainda não dominado, o aluno está inevitavelmente arriscando-se em cometer erros. Assim como errar é fato inerente ao processo de aquisição de um idioma estrangeiro, corrigir, avaliar, apontar meios de melhorar a performance do aluno também faz parte do trabalho do professor. Muito além de posicionar-se como avaliador, o professor deve assumir o papel de facilitador, de colaborador e de motivador nesse processo (GUS, 2011).

Gus (2001) pesquisou como os professores de língua estrangeira corrigem as composições realizadas por seus alunos e de que maneira são ofertados os feedbacks avaliativo e corretivo. A autora afirma que quando o professor corrige as composições de seus alunos, é necessário que se tenha muita clareza quanto aos seus critérios e que se saiba exatamente o que se deseja avaliar, para que, desta forma, os alunos se sintam mais seguros e menos ansiosos em relação à maneira como o 
feedback será ofertado por seus professores. Os estudos realizados pela autora analisaram 79 composições em língua inglesa de diferentes alunos brasileiros já corrigidas pelos seus professores. Alguns dos resultados mais expressivos indicaram que: a) os professores não adotam critérios claros de correção; b) os erros mais corrigidos referem-se à gramática, em detrimento dos demais; c) os erros relacionados à organização não são corrigidos; d) não há espaço para a reflexão e autocorreção, pois o professor oferece a resposta certa ao aluno.

Para que não aconteçam mal entendidos e até mesmo insatisfação por parte do aluno de língua estrangeira, Raimes (1983) e Hadley (2001) sugerem que deve-se decidir quais erros são prioritários de serem tratados nos diferentes momentos da aprendizagem. Desta forma, é necessário que sejam partilhados os critérios de avaliação. Combinar e discutir com o aluno a maneira como o seu erro será tratado resultará em benefícios para todos os agentes do processo de ensino e de aprendizagem (LIMA, 2003). O autor investigou os tipos, a frequência e a eficácia das estratégias de feedback ofertados por professores de espanhol como língua estrangeira. Para tal, o autor concentrou-se em estudar dois tipos de estratégias: o feedback positivo e o feedback corretivo. O estudo concluiu que geralmente considera-se que o principal papel do professor de idioma estrangeiro é o de prover a correção dos erros cometidos pelos aprendizes, ofertando feedbacks corretivo e positivo ou de aprovação à produção linguística dos alunos.

Ellis (1997) afirma que os erros e a promoção de feedback corretivo constituem um aspecto natural do processo de ensinar e de aprender. O autor descreve como erros os desvios da norma lingüística da língua alvo. Os erros revelam em que estágio de desenvolvimento dos sistemas intra-linguísticos os alunos se encontram, mostrando onde os alunos generalizaram as normas ou regras da língua estrangeira ou onde houve a inadequada transferência ou influência da língua materna sobre a língua estrangeira (LIGHTBOWN; SPADA, 1999). Os autores apontam que o professor promove o feedback corretivo para indicar ao aluno que houve erro ao se usar a língua alvo, e, para isso, o instrutor utiliza uma variedade de respostas. Segundo eles, o feedback corretivo pode ser explícito, (“No, you should say goes, not go” ) ou implícito (Yes, he goes to school every day), e pode ou não conter uma informação meta-linguística ("Don't forget to make the verb agree with the subject").

Em termos cognitivos, Lightbown e Spada (1999) mencionam que a função do feedback corretivo é de oferecer informações aos alunos para que eles possam ativamente usá-las para modificar seu comportamento. Ainda segundo os autores, as informações disponíveis no feedback permitem que o aprendiz confirme, desconfirme, e, se for o caso, modifique e reconstrua as hipóteses gramaticais que vinha usando até então. Entretanto, os autores apontam que esse 
comportamento depende do estágio de desenvolvimento em que o aluno se encontra, assim como de sua habilidade em compreender as informações contidas no feedback.

De acordo com Schimidt e Frota (1986), a eficácia do feedback corretivo no ensino de língua estrangeira depende de múltiplos fatores, entre eles: (1) o que exatamente está se corrigindo no momento; (2) as condições ou a maneira em que o professor promove a correção; (3) a adequação da correção em relação ao estágio de aprendizagem em que o aluno se encontra, pois, caso contrário, o aluno não se beneficiará do feedback; e (4) a capacidade dos aprendizes em perceberem a lacuna que existe entre aquilo que eles gostariam de produzir e o que eles são realmente capazes de produzir, levando-os a diferenciar o que não sabem daquilo que sabem parcialmente.

Estudos mostram também que uma porcentagem expressiva de professores oferecem o feedback e, logo em seguida, avançam para a próxima questão, tópico ou prosseguem com outro tipo de feedback (por exemplo: corretivo, motivador, esclarecedor) sem que o aluno tenha tempo para produzir uma resposta ou confirmar o feedback. Este conceito de espera é conhecido como "wait time" (traduzido como "tempo de espera") (ROWE, 1969). O autor estudou o tempo de espera em crianças nativas da língua inglesa em aulas de ciências. A autora concluiu que à medida em que o professor aumentava o tempo de espera, a qualidade e a quantidade de respostas formuladas pelos alunos aumentavam.

Em pesquisas relacionadas ao mesmo tema, Holley e King (1971) pediram para que professores de alemão como segundo idioma aguardassem de cinco a dez minutos se um aluno cometesse um erro ou hesitasse em responder a uma questão. Os autores concluíram que em mais de $50 \%$ dos casos os professores nem precisaram ofertar feedback corretivo ou se esforçarem em auxiliar seus alunos a formular respostas coerentes. Ao receberem um breve tempo adicional, os próprios alunos são capazes de responder às questões corretamente (ROWE, 1969; HOLLEY; KING, 1971; FANSELOW, 1977; ALLWRIGHT; BAILEY, 1991).

\section{CONCLUSÕES}

Esta pesquisa foi conduzida com o objetivo de verificar como os professores de língua estrangeira fornecem o feedback aos seus alunos. Foi pesquisado qual é o caráter pedagógico que professores, coordenações pedagógicas e instituições de ensino imprimem ao feedback. Além disso, investigou-se como o aluno recebe o feedback, de que forma reage ao recebê-lo e de que maneira o feedback tem sido relevante para o seu desenvolvimento educacional.

De acordo com a análise da literatura especializada, constatou-se que os professores não têm critérios claros e bem definidos para oferecer feedback aos seus alunos. Os professores sentem- 
se desmotivados em prover feedback avaliativo e motivacional aos seus alunos por diversas razões, entre elas: pela falta de conhecimento acerca dos benefícios de sua prática, por excesso de trabalho, em uma jornada diária cansativa e extensa, pela falta de comprometimento por parte dos alunos em seguirem as orientações contidas nos feedbacks, e por não receberem incentivo por parte das respectivas coordenações pedagógicas e das direções de ensino.

É fundamental que o aluno conheça os resultados de suas práticas educacionais e de seu desempenho. Considerando o fato de que os indivíduos constroem os seus conhecimentos através da dinâmica dos diálogos, que são permeados por contradições, argumentações, trocas e buscas solidárias, a avaliação do processo de ensino e da aprendizagem é essencial, tanto para o aluno como para o professor.

A fim de que haja uma avaliação transparente e justa, o professor deve definir claramente o que pretende observar ao oferecer feedback, pois somente com a clareza dos seus critérios é que professores e alunos poderão se beneficiar desta prática pedagógica e favorecer o aprimoramento do ensino e da aprendizagem. Discutir os critérios de avaliação previamente de forma esclarecedora resulta em um bom relacionamento entre o professor e o aluno (LIMA, 2003). Tal conduta fortalece os laços de confiança e respeito entre todos os agentes educacionais envolvidos no processo de ensino e de aprendizagem.

É importante que o professor de língua estrangeira tenha a clareza de que o erro é inerente ao processo de aprendizagem. Desta forma, ao utilizar o feedback de forma avaliativa e motivadora, o erro deixará de receber uma conotação de derrota e de ineficiência, e passará a ser visto como uma oportunidade para o acerto.

\section{REFERÊNCIAS}

ABAURRE, M. B. M.; ABAURRE, M. L. M. A avaliação objetiva de produções escritas. Ciências e Letras, Porto Alegre, v. 26, p. 141-159, 1999.

ALLWRIGHT, R.; BAILEY, K. M. Focus on the language classroom. Cambridge: Cambridge University Press, 1991.

BATTISTICH, V. et al. Prevention effects of the Child Development Project: Early findings from an ongoing multi-site demonstration trial. Journal of Adolescent Research,Oakland, v.11, n. 1, p. 12-35, jan., 1996.

BIRCH, S.H.; LADD, G. W. The teacher-child relationship and children's early school adjustment. Journal of School Psychology, v. 35, n. 1, p. 61-79, out.,1997.

BLOTE, A. W. Students' self-concept in relation to perceived differential teacher treatment. Learning and Instruction, Washington, v. 5, n. 3, p. 221-236, 1995. 
BORDENAVE, J. E. D. O que é comunicação. São Paulo: Brasiliense, 1982.

BRITO, I.; HADDAD, H. A formulação do conceito de homeostase por Walter Cannon. Filosofia e História da Biologia, São Paulo, v. 12, n. 1, p. 99-113, jan/jun., 2017.

BROPHY, J. Teacher praise: a functional analysis. Review of Educational Research, v. 51, n.1, p. 5-32, mar., 1981.

BYRNE, D. Teaching writing skills. New York: Longman, 1988.

CARDOSO, A. C. S. Feedback em contextos de ensino-aprendizagem on-line. Linguagens e Diálogos, Rio de Janeiro, v. 2, n. 2, p. 17-34, 2011.

CHO, K.; SCHUNN, C. D. Scaffolded writing and rewriting in the discipline: a webbased reciprocal peer review system. Computers \& Education, v. 48, n. 3, p. 409-426, abr., 2005. Disponível em: <http://www.lrdc.pitt.edu/schunn/research/papers/cho-schunn-CE.pdf >. Acesso em: 4 abr. 2013.

COHEN, A. D.; CAVALCANTI, M. C. Feedback on compositions: teacher and student verbal reports. In: KROLL, B. (Ed.). Second language writing: research insights for the classroom. Northridge: Cambrigde University Press, 1990, p. 155-177.

COUPE, N. Evaluating teachers' responses to children's writing. In: HARRIS, J.; WILLKINSON, J. (Eds.). Reading children's writing: a linguistic view. London: Allen and Uniwin, 1986. p. 122144.

DHERAM, P. K. Feedback as a two-bullock cart: a case studying of teaching writing. ELT Journal, Oxford, v. 49, n.2, p. 160-168, abr., 1995.

DUNKIN, M.; BIDDLE, B. The study of teaching. New York, NY: Holt, Rinehart \& Winston, 1974.

DVORAK, T. Writing in the foreign language. In: WING, B. (Ed.). Listening, reading, writing: analysis and application - Reports of the Northeast Conference on the teaching of foreign languages. Middlebury: Northeast Conference, 1986. p. 145-167.

EDGE, J. Mistakes and correction. 2. ed. New York: Longman, 1989.

ELLIS, R. The Study of second language acquisition. Oxford: Oxford University Press, 1997.

ERTMER, P. A. et al. Using peer feedback to enhance the quality of students' online postings: An Exploratory Study. Journal of Computer-Mediated Communication, v. 12, n. 2, article 4. 2007. Disponível em: <http://jcmc.indiana.edu/vol12/issue2/ertmer.html〉. Acesso em: 4 abr. 2013.

FANSELOW, J. The treatment of learner error in oral work. Foreign Language Annals, v.10, n. 5, p. 583-593, out., 1977.

FLORES, A. M. O feedback como recurso para a motivação e avaliação da aprendizagem na educação a distância. Congresso ABED 2009. Palhoça, p. 1-10, mar., 2009. Disponível em: 
<http://www.abed.org.br/congresso2009/CD/trabalhos/1552009182855.pdf>. Acesso em: 4 abr. 2013.

FRASER, B. J. Two decades of classroom research. In: FRASER, B. J.; WALBERG, H. J. (Eds.). Educational environments: evaluation, antecedents, and consequences. 1. ed., New York: Pergamon Press, 1991. p. 3-27.

GUS, C. O feedback avaliativo e corretivo em composições de língua inglesa analisadas por professores não-nativos. 2001. 123 f. Dissertação (Mestrado em Estudos da Linguagem) Universidade do Rio Grande do Sul, Porto Alegre, 2001.

HADLEY, A. O. Teaching language in context. 3 ed., Boston: Heinle \& Heinle, 2001.

HATTIE, J. Measuring the effects of schooling. SET, v.2, p.1-4, 1993.

HEDGE, T. Writing. Teaching and learning in the language classroom. Oxford: Oxford University Press, 2001.

HENDRICKSON, J. M. HEDGE, T. Writing, teaching and learning in the language classroom. Oxford: Oxford University Press, 2000.

HITZ, R.; DRISCOLL, A. Praise or encouragement? New insights into praise: implications for early childhood teachers. Young Children, Washington, v. 43, n. 5, p. 6-13, jul., 1988.

. Give encouragement, not praise. Texas Child Care, Austin, v. 17, n. 4, p. 2-11, 1994.

HOLLEY, F. M.; KING, J. K. Imitation and correction in foreign language learning. The Modern Language Journal, v. 55, n. 8, p. 494-498, dez., 1971.

HYLAND, K. Providing productive feedback. ELT Journal, Oxford, v. 44, n. 4, p. 279-285, out., 1990.

JAMES, C. Errors in language learning and use: exploring error analysis. New York: Longman, 1998.

KEH, C. L. Feedback in the writing process: a model and methods for implementation. ELT Journal, Oxford, v. 44, n. 4, p. 294-304, out., 1990.

KIELTY, L. S. Feedback in distance learning: do students perceptions of corrective feedback affect retention in distance learning? 2013. 66 f. Monografia (Especialização em Educação) - University of South Florida, 2004. Disponível em: <http://scholarcommons.usf.edu/etd/1114>. Acesso em: 28 abr. 2013.

LANGAN, A. M.; WHEATER, C. P. Can students learn effectively? Some insights into peer assessment. Learning and teaching in action, Manchester, v. 2, n. 1, dez., 2003.

LIGHTBOWN, P.; SPADA, N. How languages are learned. Oxford: Oxford University Press, 1999. 
LIMA, M. S. Corrective feedback and learner autonomy in the foreign language classroom. In Fórum Internacional de Ensino de Línguas Estrangeira, 2, 2003, Pelotas. Anais ... Pelotas: UCPEL, 2003, v.1, p. 378-395.

LUCE, S.; HOGE, R. Relations among teacher rankings, pupil-teacher interactions, and academic achievement: A test of the teacher expectancy hypothesis. American Educational Research Journal, v. 15, n. 4, p. 489-500, nov., 1978.

LYSTER, R.; RANTA, L. Corrective feedback and learner uptake: negotiation of form in communicative classrooms. Studies in Second Language Acquisition, v. 19, n. 1, p. 37-66, 1997.

MASON, B.; BRUNING, R. Providing feedback in computer-based instruction: what the research tells us. Class Project Research Report n. 9, jan., 2001. Disponível em: < https://www.researchgate.net/publication/247291218_Providing_Feedback_in_Computerbased_Instruction_What_the_Research_Tells_Us> Acesso em: 28 mar. 2013.

MERRETT, F.; WHELDALL, K. Natural rates of teacher approval and disapproval in British primary and middle school classrooms. British Journal of Educational Psychology, v. 57, n. 1, p. 95-103, fev., 1987.

. Teachers' use of praise and reprimands to boys and girls. Educational Review, Londres, v. 44, n. 1, p. 73-79, jul., 2006.

PAIVA, V. L. M. O. (2003). Feedback em Ambiente Virtual. In: LEFFA, V. (Org.) Interação na aprendizagem das línguas. Pelotas: EDUCAT, 2003, p. 219-254. Disponível em:

<http://www.veramenezes.com/feedback.htm>. Acesso em: 28 mar. 2013.

PAN, A. A expressão oral e escrita. Porto Alegre: Audivisão Produções, 1980.

PIANTA, R.C.; WALSH, D.J. High-risk children in schools: Constructing sustaining relationships. New York: Routledge, 1996.

PORLIER, P.; SAINT-LAURENT, L.; PAGE, P. Social contexts of secondary classrooms and their effect on social competence and social adjustment of students with learning disabilities. Annual Meeting of the American Educational Research Association, Quebec, Canadá, 1999. Disponível em: < https://files.eric.ed.gov/fulltext/ED431273.pdf> Acesso em: 09 abr. 2013.

RAIMES, A. Techniques in teaching writing. New York: Oxford University Press, 1983.

RINVOLUCRI, M. Key Concepts in ELT: feedback. ELT Journal, Oxford, v. 48, n. 3, p. 287-288, jul., 1994.

ROWE, M. B. Science, soul and sanctions. Science and Children, v. 6, n. 6, p. 11-13, 1969.

SCHERMAN, J. Feedback. Oxford: Oxford University Press, 1994.

SCHIMIDT, R. W.; FROTA, S. N. Developing basic conversational ability in a second language: a case study of an adult learner of Portuguese. In: DAY, R. R. (Ed.) Talking to learn: conversation in second language acquisition. Massachusets: Newbury House, 1986. p. 237-326. 
SCHRIVER, K. A. Evaluating text quality: the continuum from text-focused to reader-focused methods. IEEE Transactions on Professional Communication, v. 32, n. 4, p. 238-255, dez., 1989.

SHERPELL, W. Health Quest: A quarterly newsletter focusing on mental health issues and concerns, 2000. Disponível em: <http://www.warrenshepell.com/articles/praise.html> Acesso em: 8 abr. 2014.

SHUTE, V. J. Focus on formative feedback. Review of Educational Research. v. 78, n. 1, p. 153189, mar., 2008.

SOUSA, M. B. C.; SILVA, H. P. A.; GALVÃO-COELHO, N. L. Resposta ao estresse: I. Homeostase e teoria da alostase. Estudos de Psicologia, Natal, v. 20, n. 1, p. 2-11, jan./mar., 2015.

STRAIN, P.S. et al. Naturalistic assessment of children's compliance to teachers' requests and consequences for compliance. Journal of Applied Behavior Analysis, v. 16, n. 2, p. 243-249, jul., 1983.

THAC SĨ, L.V. The impact of online peer feedback on EFL learner's motivation in writing performance: a case study at Can Tho University, 2008. 89 f. Dissertação (Mestrado em Educação) - Can Tho University, Can Tho, 2008.

TRAHASCH, S. From Peer Assessment Towards Collaborative Learning. $34^{\text {th }}$ Annual Frontiers in Education Conference, 2004. FIE 2004.. v. 2, p. 16-20.

THOMAS, J. You're the greatest! A few well-chosen words can work wonders in positive behavior reinforcement. Principal, v. 71, p. 32-33, 1991.

THOMAS, J. D.; PRESLAND, I. E.; GRANT, M. D.; GLYNN, T. L. Natural rates of teacher approval and disapproval in grade-7 classrooms. Journal of Applied Behavior Analysis, v. 11, n. 1, p. 285-303, 1978.

THORP, H. S.; BURDEN, R. L.; FRASER, B. J. Assessing and improving classroom environment. School Science Review, v. 75, p. 107-113, mar., 1994.

UR, P. A course in language teaching: practice and theory. 2. ed. Cambridge: Cambridge University Press, 1996.

VRASIDAS, C.; McISAAC, M. S. Factors Influencing Interaction in an Online Course. American Journal of Distance Education, v. 13, n. 3, p. 22-36, 1999.

WANG, M. C.; HAERTEL, G. D.; WALBERG, H. J. What influences learning? A content analysis of review literature. Journal of Educational Research, Washington, v. 84, n. 1, p. 30-43, 1994.

WENTZEL, K. R. Relations of social goal pursuit to social acceptance, classroom behavior, and perceived social support. Journal of Educational Psychology, cidade, v. 86, n. 2, p. 173-182, jun., 1994.

WILLIAM, R. L. Preciso saber se estou indo bem: uma história sobre a importância de dar e receber feedback. Rio de Janeiro: Sextante, 2005. 
WUBBELS, T.; LEVY, J. Do you know what you look like? Interpersonal relationships in education. Washington: Falmer Press, 1993. 